\title{
A MORALIDADE TEM UMA CHANCE NA CONCEPÇÃO DA ETICIDADE DE HEGEL?
}

\author{
Christian Iber ${ }^{1}$
}

\section{Resumo:}

O artigo discute a posição de Hegel segundo a qual a moralidade, com efeito, representa uma compreensão importante do direito e da liberdade, porém que não é a definitiva, mas é sobrepujada pela compreensão ética do direito e da liberdade. Na moralidade se trata do direito e da liberdade de adquirir sua orientação de vida pela autodeterminação subjetiva, em que os sujeitos singulares podem reivindicar estabelecer uma distinção entre "correto" e "falso", "bem" e "mal" a partir de si mesmos. Na sua crítica à moralidade, Hegel aduz o direito e os limites do direito da compreensão moral da liberdade. Com sua crítica da moralidade Hegel prepara o solo para sua concepção da eticidade, na qual a compreensão da liberdade dos sujeitos singulares se forma pela orientação nas instituições da comunidade ética. A vontade e a ação são compreendidas como expressão de uma compreensão da liberdade coletivamente praticada. Hegel não trata da restauração da eticidade antiga que ainda não conhece a liberdade moral, mas de uma nova forma da eticidade estatal que pode ser realizada sob as condições da Modernidade. Vale examinar se e em que maneira Hegel cumpre a integração da moralidade na sua concepção da eticidade, a qual é exigida por ele mesmo. Nesse caso, mostra-se que Hegel integra a moralidade apenas em um sentido eticamente não específico na eticidade estatal, segundo o qual a vontade subjetiva deve identificar-se com as instituições estatais; à parte disso, ele entrega a moralidade ao âmbito da sociedade burguesa, na qual ela empresta serviços úteis de compensação para o Estado, que considera supérflua a assistência político-social dos pobres.

Palavras-chave: Moralidade, Direito, Liberdade, Eticidade, Estado.

\begin{abstract}
:
The article discusses Hegel's opinion that morality, in effect, represents an important understanding of right and freedom, although it is not definitive, it is surpassed by the ethical understanding of right and freedom. In morality, we deal with the right and freedom to acquire life orientation by the subjective self-determination, in which the singular subjects can claim to establish a distinction between "correct" and "false", "good" and "evil" from themselves. In Hegel's critique of morality, he presents the right and the limits of the right of freedom moral understanding. Through his critique about the morality, Hegel prepares the land for his conception of ethics, in which the singular subject's understanding of freedom is formed by the guidance in institutions of the ethical community. The will and action are understood as expression of an understanding of freedom collectively practiced. Hegel does not discuss on the restoration of the ancient ethics that does not know the moral freedom yet, but he does it
\end{abstract}

\footnotetext{
${ }^{1}$ Doutor em Filosofia e professor do Institut für Philosophie da Freie Universität Berlin/AL. Professor Visitante do Programa de Pós-graduação em Filosofia da PUC-RS. Bolsista CAPES.
} 
in a new way of State ethics that can be performed under the Modernity conditions. It is worth examining whether and how Hegel fulfills the integration of morality in his conception of ethics, which is required by him. In this case, we can realize that Hegel integrates morality only in a sense ethically non specific in government ethics, according to which the subjective will may identify itself with the state institutions; apart from this, he leaves the morality under the bourgeois society and it lends useful compensation services for the State, that considers superfluous the political and social assistance given to the poor.

Keywords: Morality, Right, Freedom, Ethics, State.

Para chegar ao conhecimento da relação da moralidade e da eticidade na Filosofia do Direito de Hegel, procedo em quatro passos. Em primeiro lugar, delineio a compreensão de Hegel da moralidade e, em segundo lugar, sua crítica da moralidade. Num terceiro momento, esclareço a transição da moralidade para a eticidade e, num quarto momento, trato da questão se Hegel consegue integrar o ponto de vista da moralidade na sua concepção da eticidade.

\section{O que Hegel compreende sob moralidade?}

A moralidade fica entre o âmbito do direito abstrato e da eticidade. ${ }^{2}$ Hegel compreende a eticidade como síntese do direito e da moralidade. A moralidade caracteriza o ponto de vista da Modernidade que se origina com a consciência cristã do valor infinito de cada sujeito. A distinção entre a moralidade e a eticidade corresponde à diferença entre a sociedade burguesa e o Estado. Consequentemente, a moralidade é relacionada à sociedade burguesa. Hegel a denomina como "eticidade do bourgeois ou do homem privado". 3 O direito da liberdade do sujeito singular forma o núcleo conjunto da moralidade e da sociedade burguesa.

Sob a moralidade Hegel compreende três coisas distintas: primeiramente, ele discute a compreensão da moralidade que ainda não lhe atribui uma significação que

\footnotetext{
2 Sob o título "o direito abstrato", Hegel discute as normas do direito civil e penal (G.W.F. Hegel, Grundlinien der Philosophie des Rechts oder Naturrecht und Staatswissenschaft im Grundrisse [Princípios da filosofia do direito ou direito natural e ciência do Estado em compêndio] [Sigla: FdD]. In: Werkausgabe in zwanzig Bänden, E. Moldenhauer, K.M. Michel (Orgs.), Vol. 7. Frankfurt am Main: Suhrkamp, 1969ss. [Sigla: $H W], \S \S 34-104$.

${ }^{3}$ G.W.F. Hegel, Über die wissenschaftlichen Behandlungsarten des Naturrechts, seine Stelle in der praktischen Philosophie und sein Verhältnis zu den positiven Rechtswissenschaften [Sobre as maneiras científicas de tratar o direito natural, seu lugar na filosofia prática e sua relação com as ciências positivas do direito]. In: HW2, 506.
}

\begin{tabular}{|c|c|c|c|c|}
\hline Qevista Dialectus & Ano 2 & n. 3 & Julho-Dezembro 2013 & p. $35-47$ \\
\hline
\end{tabular}


está relacionada ao bem ético, mas diz respeito ao aspecto universalizável da ação autodeterminada ( $F d D \S \S 105-114$ ). A moral é uma compreensão da liberdade, em consequência disso a vontade do sujeito singular orientada normativamente pela universalidade se identifica com os seus propósitos e as suas pretensões, porque ela tem nelas a expressão autêntica de si mesma. ${ }^{4}$ Com essa compreensão da moralidade Hegel reivindica delinear os momentos da compreensão natural ou comum da moralidade. Em um segundo momento, primeiramente é tematizada a ética do dever e da disposição de espírito de Kant que se relaciona ao bem ético ( $F d D \S \S 129-135)$. Em um terceiro momento Hegel discute a ética da consciência subjetiva (FdD §§ 136-140). ${ }^{5}$

\section{Aspectos da crítica da moralidade de Hegel}

A crítica de Hegel à moralidade consiste no fato de que ele explica o direito da liberdade moral e seus limites. Esse limite a liberdade encontra moralmente no âmbito da liberdade ética que os sujeitos singulares desenvolvem em orientação pelas instituições da comunidade ética. Hegel não está voltado à restauração da eticidade antiga, que ainda não conhece a liberdade moral do sujeito, mas a uma nova forma da eticidade do Estado que pode ser realizada sob as condições da Modernidade. Vale examinar se Hegel resgata a exigência da integração da moralidade na sua concepção da eticidade.

Sobre a moralidade que ainda não está relacionada ao bem ético, discute-se a vontade do sujeito singular que se relaciona criticamente com as oposições da realidade social que são organizadas pela universalidade do direito abstrato assim que a própria liberdade experimenta sua barreira na liberdade dos outros indivíduos. O tema são as finalidades da ação da vontade do sujeito singular que está orientado normativamente pela relação à universalidade e, por isso, também contém uma referência positiva à vontade dos demais sujeitos. ${ }^{6}$ Contudo, na moralidade, a universalização da subjetividade se depara com barreiras. ${ }^{7}$

A moralidade levanta todas as oposições na sociedade burguesa em um grau superior, na medida em que ela obriga os interesses, que são opostos uns aos outros, a

\footnotetext{
${ }^{4} \mathrm{O}$ direito da liberdade subjetiva-moral é articulado pelo princípio do próprio-estar-nisso-e-presente numa ação ("interest mea, ut ego intersim" $[F d D \S 107 \mathrm{~N}]$ ).

${ }^{5}$ Um panorama sobre o item da moralidade da Filosofia do Direito de Hegel dá Christoph Jermann (1987, 101-144).

${ }^{6}$ Para o conceito de ação moral cf. $F d D \S \S 108-112$.

${ }^{7}$ Para a universalização da subjetividade na moralidade e seus limites cf. $F d D \S 112$.
} 
uma universalidade que se verifica, contudo, como fictícia, porque todos os indivíduos também retêm os seus interesses próprios. ${ }^{8} \mathrm{O}$ sujeito moral confronta os outros com a pergunta: se suas próprias finalidades teriam propriamente seu objetivo na concordância com todos os outros indivíduos, logo, com a exigência da moralidade. Ao mesmo tempo, ele chega ao conhecimento que a hipocrisia está sempre em jogo e em todos os lados. O recurso a um universal moral é apenas o método para a produção da aparência da validade universal do próprio interesse particular. As oposições dos interesses que são negados moralmente prosperam aparentemente no signo do universal moral, porque sua negação, a cobrança moral da parte contrária, não é nenhum abandono das próprias finalidades particulares.

A sociedade burguesa é, para Hegel, uma sociedade moralizada por si, na qual o interesse na própria moralidade e na moralidade dos outros se afirma necessariamente por causa da universalidade do direito abstrato que prescreve as colisões do interesse particular dos indivíduos sob a observação e o reconhecimento da pessoa e da propriedade. Hegel reflete, portanto, a conexão entre o direito e a moralidade. ${ }^{9}$ Todo interesse se afirma como moralmente refletido. Ele tenta proporcionar-se legitimidade, na medida em que ele se relaciona com um valor universal moral, sem que, com isto, as oposições dos interesses sejam eliminadas.

Resumindo os pensamentos até agora desenvolvidos: como sujeitos morais, os indivíduos da sociedade burguesa completam sua relação negativa de um para o outro, codificada no direito abstrato, como pessoas privadas e proprietários pela relação positiva de um para o outro no roteiro da sua orientação normativa por um universal, sem que essa relação positiva de um para o outro possa ganhar objetividade, porque ela depende do seu ponto de vista subjetivo. O universal da moralidade é apenas um universal subjetivo particular, um universal que resulta da subjetividade moral em vez de ser seu fundamento substancial.

Esse padrão geral do movimento da moralidade é esclarecido por Hegel no ponto de vista moral do utilitarismo ( $F d D \S \S 123-128)$. A preocupação pelo próprio bem-estar vale normalmente apenas, então, como intenção moral quando ela cuida também do bem-estar dos outros. O momento normativo do universal do bem-estar dos outros é essa referência da vontade particular ao bem-estar de outros, ao bem-estar de

\footnotetext{
${ }^{8}$ Tais valores morais ou ideais gerais são: modéstia, honestidade, retidão, altruísmo, compaixão, amor ao próximo, solidariedade, sentido de comunidade, humanidade, salubridade, tolerância etc.

${ }^{9}$ Para a relação entre o direito e a moralidade cf. $F d D \S \S 103,104$.
} 
muitos ou até mesmo de todos os outros. O fraco do ponto de vista utilitarístico do bem-estar reside, para Hegel, no seu caráter da particularidade casual. No ponto de vista do bem-estar, com efeito, o sujeito está além da sua própria privacidade, na medida em que ele liga aditivamente o interesse no próprio bem-estar com o bem-estar dos outros. Contudo, a promoção do bem-estar particular dos outros, a relação positiva aos outros sujeitos, permanece indeterminada. Finalmente, cada pessoa cria sua própria sorte na vida. $\mathrm{O}$ bem-estar dos outros permanece entregue ao engajamento privado da vontade particular.

$\mathrm{Na}$ moral do bem-estar, a universalidade da subjetividade é rebaixada à particularidade. Primeiramente, o bem-estar dos outros é uma particularidade, secundariamente, ele mostra-se como mera extensão do próprio bem-estar privado. Em terceiro lugar, se torna saliente que o bem-estar dos outros está subordinado ao próprio bem-estar particular. Precisamente essa concepção totalmente não-kantiana explicita que Hegel contrasta a moral praticada na sociedade burguesa com a sua reflexão teórica na filosofia da moral de Kant. A moral praticada sustenta o ponto de vista de uma moral privada egoísta ainda no altruísmo.

Como resultado intermédio se deixa reter o seguinte: a crítica da moralidade de Hegel diz que a partir de si a vontade subjetiva moral não pode levar a uma universalidade estável. A universalidade da vontade lhe jaz antes como objetiva no Estado. Isto Hegel mostra, na medida em que ele aponta que a vontade subjetiva, que se forma moralmente à universalidade, cai no nível da particularidade. A universalidade da vontade do sujeito singular permanece sendo uma universalidade subjetiva. A domesticação moral da subjetividade moderna não pode, neste instante, ser realizada somente por essa subjetividade. ${ }^{10}$ Por isso se torna necessário a concepção da eticidade, a integração da subjetividade moral em uma universalidade substancial que se lhe antecipa.

Hegel abre sua crítica à concepção da moralidade de Kant com uma antecipação do bem ético que é determinado como unidade da vontade universal e particular, do direito e do bem-estar, isto é, como o bem-estar público do Estado ( $F d D \S \S 129-130)$. O sentido dessa antecipação consiste em explicitar que o bem da moralidade é o bem emprestado da eticidade que ela não pode produzir a partir de si mesma. A crítica da moralidade, que averigua o direito e os limites do direito da moralidade, volta-se contra

\footnotetext{
${ }^{10}$ Cf. O próprio resumo de Hegel da exposição da moralidade no $F d D$ §§ 113-114.
} 
o ponto de vista da moralidade que se separa da eticidade, à qual a moralidade deve sua categoria ética fundamental.

O bem moral é, frente ao bem ético, apenas o bem abstrato, porque a vontade particular é ainda algo independente contra o bem, por conseguinte, fica tão-somente em uma relação de dever-ser para com o bem. O bem moral é o devendo-ser da vontade do sujeito singular, e ele adentra apenas neste na realidade $(F d D \S 131)$. O conceito de bem moral contém o "direito da vontade subjetiva [...] que o que ela deve reconhecer como válido seja por ela discernido como bom" (FdD § 132). Com isso se efetua uma recondução da vontade do sujeito singular na autonomia moral da subjetividade.

O direito da autonomia moral é, sem dúvida, para Hegel, o direito máximo do sujeito, precisamente que ele mesmo seja, de fato, o fundamento jurídico da norma moral. Contudo, Hegel vê na autonomia da subjetividade moral também a fonte dos riscos políticos. Por isso, ele restringe o direito do sujeito à autonomia moral, na medida em que ele o confronta com o "direito do racional enquanto direito do objetivo sobre o sujeito" ( $F d D \S 132$, Anotação): o direito da objetividade do Estado. O sujeito, que encontra uma instância orientadora somente na sua própria razão prática na figura do imperativo categórico, não deve se sobrepor ao objetivo legal e ao direito vigente do Estado.

Para Kant deve ser perguntado: o que quer uma boa vontade? A boa vontade quer o que pode ser, ao mesmo tempo, um dever. A relação positiva do bem com a vontade é, portanto, a relação de uma obrigação, de uma obrigatoriedade da vontade do sujeito singular como vontade universal contra si como vontade particular. Como aspecto positivo na concepção da moral de Kant, Hegel corrobora que Kant destaca a autonomia da razão da vontade como o único fundamento do dever. O dever é a finalidade da vontade que pode ser, ao mesmo tempo, uma lei universal, uma lei que a vontade singular dá a si mesma.

A crítica de Hegel à concepção da moral de Kant contém, além da restrição da autonomia da subjetividade moral, os três seguintes pontos ( $F d D \S \S 133-135)$ :

1. A crítica do intensionalismo: o bem moral e o dever permanecem em Kant na interioridade da subjetividade moral. $\mathrm{O}$ objeto dos predicados morais são somente as intenções interiores das ações, não o sucesso exterior ou as consequências das ações. No entanto não é suficiente para Hegel querer o bem ou o dever como finalidade, mas é preciso também fazer ambos. A interioridade moral da subjetividade tem que se abrir para o mundo ético, para que ela se torne substancial. 
2. A crítica do formalismo: o imperativo categórico é, como regra da universalização para fins da universalização das máximas da ação, um formalismo, do qual os deveres concretos, conteudísticos, não se deixam deduzir suficientemente. Concebido como aquilo que resta quando todos os conteúdos especiais da vontade são abstraídos, o imperativo categórico não é nenhum princípio gerador dos deveres determinados e, ao mesmo tempo, aplicável a todos os conteúdos. Com o critério formal da identidade e da liberdade da contradição, não se pode adquirir conteúdos determinados, que são o bem ou o dever. Esses conteúdos estão, antes pelo contrário, pressupostos. Mas, com isso, seria exatamente pressuposto ao exame moral também aquilo que deveria ser o seu resultado. $^{11}$

3. A crítica do rigorismo: a regra da universalização do imperativo categórico que purifica os pontos de vista especiais da sua particularidade e os eleva ao ponto de vista da universalidade e da imparcialidade se baseia na oposição do universal e do particular na vontade do sujeito singular. Isso significa que a norma universal posta pela vontade singular é sempre uma obrigatoriedade para ela enquanto vontade particular. Essa oposição do universal e do particular na vontade do sujeito singular deve, para Hegel, ser suprassumida. Isso, contudo, não se dá pelo fato de que a vontade particular adquire em si mesma a qualidade da universalidade, mas se dá na medida em que ela se assemelha à vontade universal a partir de si mesma e se torna realidade da vontade universal.

Porque seu princípio da universalização não serve à determinação dos deveres concretos, a concepção da moral de Kant resulta, para Hegel, em um subjetivismo decisionista da consciência moral, em que a arbitrariedade do sujeito singular se eleva à instância absoluta da decisão sobre o bem e o mal. A crítica da moral de Hegel culmina, com isso, na crítica do subjetivismo moral da consciência, na medida em que ele esboça a história da depravação do bem moral e sua inversão no egoísmo comodista (FdD §§ 136-140). O mal é uma implicação necessária da determinação do bem moral fundamentada tão-somente na consciência subjetiva. Assim como a iniquidade se mostra como verdade sobre o direito abstrato, também o mal, o egoísmo comodista, se

\footnotetext{
${ }^{11}$ A exterioridade principal do princípio da moralidade em relação aos deveres concretos vale também para outras versões desse princípio: Se se deve pensar sempre também no bem-estar dos outros, o que se faz, então, de bom para eles? Também em relação ao imperativo do acordo da ética comunicativa da solução do conflito não se sabe o que o princípio postula concretamente, apenas que os oponentes do conflito devem entrar em consenso. Contudo, no que eles devem consensuar? Quem tem que ceder, quem não; quem tem que ceder mais, quem deve ceder menos? A filosofia moderna da moral trata essencialmente da fundamentabilidade das normas, sem expor-se ao embaraço fundamentar realmente uma única.
}

\begin{tabular}{|c|c|c|c|}
\hline Qevista Dialectus & Ano 2 & n. 3 & Julho-Dezembro 2013 \\
\hline
\end{tabular}


mostra como verdade sobre o ponto de vista moral. A fenomenologia das figuras da consciência moral mostra que a tentativa dos sujeitos singulares de determinar o bem abstrato a partir de si mesmos e, assim, realizar a unidade da vontade universal e particular termina na negação total do bem. A consciência subjetiva, portanto, não é capaz de estabelecer uma distinção objetivamente obrigatória entre o bem e o mal.

\section{Transição para a eticidade}

Hegel tem a posição de que com esse resultado negativo ao mesmo tempo está alcançada positivamente a transição da moralidade para a eticidade. ${ }^{12} \mathrm{O}$ resultado negativo contém o círculo vicioso do seguinte problema: $\mathrm{O}$ bem indeterminado deve ser determinado pela consciência, e a consciência determinante deve ser determinada pelo bem. Para que a consciência se torne ética, ela teria que orientar-se pelo bem efetivo, mas isso, por outro lado, teria que ser determinado, por sua vez, primeiramente pela consciência. ${ }^{13}$

Ora, é fácil demonstrar que a concepção de Hegel da transição fracassa. Ele não pode resolver o círculo vicioso do problema, porque ele cai em um outro círculo vicioso. Em vez de desenvolver o saber dos sujeitos sobre o bem efetivo, que se socializam em uma comunidade ética, ele pressupõe simplesmente a unidade ética de um bem objetivo e da consciência subjetiva que deveria ser provada.

A consciência dos sujeitos morais se depara com o princípio do bem incorporado nas instituições da eticidade, o qual ela quis determinar inteiramente a partir de si mesma. Hegel não supera, portanto, o círculo vicioso do problema entre o bem efetivo e a consciência subjetiva, porque ele compreende o bem ético que a consciência deve aprovar como encontrado. Ele se dá por satisfeito, portanto, com a alternativa: ou a subjetividade moral ou a eticidade objetivamente existente. Ele vai de encontro, com isso, ao terceiro caminho que tanto supera a subjetividade moral como evita a entrega dos sujeitos à eticidade objetivamente encontrada. Deveria ser exigido o desenvolvimento de um saber social em torno do bem efetivo como guia de uma prática

\footnotetext{
${ }^{12}$ A transição da moralidade para a eticidade Hegel trata na $F d D \S 141$.

${ }^{13}$ Para o círculo vicioso na consideração de Hegel acerca da transição da moralidade para a eticidade cf. Friederike Schick (1995, p. 65s).
} 
racional da comunidade dos sujeitos singulares que chegam a acordo quanto à capacidade da universalização dos seus interesses particulares. ${ }^{14}$

\section{Eticidade e moralidade}

Hegel emprega a expressão arcaica "eticidade" no sentido da expressão grega "ethos" que significa uma orientação da vida fundada no costume, no convencionalismo e na proveniência. ${ }^{15}$ A eticidade é, para Hegel, uma comunidade integrada, na qual a vontade e a ação dos indivíduos singulares são a expressão de uma compreensão conjuntamente praticada da liberdade. Na verdade, essa compreensão da liberdade dos sujeitos está caracterizada pela relação assimétrica de poder e domínio. Ela está fundada no poder da substância ética da comunidade, que rege a vida dos indivíduos como seus acidentes (FdD $\S \S 144-145) .{ }^{16}$

A estrutura da eticidade tem três aspectos: ${ }^{17}$

1. As instituições e os estabelecimentos da comunidade ética são objetivos e substanciais, na medida em que eles são determinados independentemente dos sujeitos singulares. Hegel vira o princípio da sua crítica da moral, colocando que os sujeitos singulares não podem estabelecer nenhuma distinção objetivamente obrigatória entre o bem e o mal a partir de si mesmos, de tal modo que uma universalidade da vontade

\footnotetext{
${ }^{14}$ Hegel liga o princípio da subjetividade a um fundamento substancial que lhe escapa. O princípio da subjetividade é conservado apenas em sua complementaridade à substância, cuja forma da articulação ela [a subjetividade] é. A superação da unilateralidade da subjetividade como forma da depravação conduz, portanto, a uma nova unilateralidade. A alternativa a Hegel seria o conceito de subjetividade que dá a si mesma seu fundamento substancial pela sua explicação social racional. Nessa concepção, o princípio da subjetividade teria de ser congruente com os sujeitos singulares reais, cuja particularidade, seu bem-estar material, não é negada, mas afirmada. A negação da particularidade dos sujeitos singulares na filosofia do espírito de Hegel é acompanhada por uma singularização do sujeito. O sujeito verdadeiro é o sujeito infinito. Ele é singularidade, não particularidade. A subjetividade do espírito é uma crítica da particularidade dos sujeitos singulares reais. A posição ambígua de Hegel acerca do princípio da subjetividade esclarece Emil Angehrn (1989, 170-181).

${ }_{15}$ Hegel esclarece o conceito de "eticidade" e sua distinção à "moralidade" no seu escrito Über die wissenschaftlichen Behandlungsarten des Naturrechts. In: HW2, 504 e FdD § 33.

${ }^{16}$ A concepção da eticidade de Hegel contém uma contradição: por um lado, Hegel afirma que os fundamentos da eticidade seriam manifestações racionais da vontade livre. Por outro lado, ele insiste no fato de que os indivíduos não são sujeitos dessas instituições, mas são subordinados às finalidades desses "poderes éticos" (FdD § 141). Sob o conceito de "substância" se esconde o sujeito real da eticidade: o Estado soberano moderno que associa os membros da sociedade burguesa ao coletivo ético em abstração do seu fazer e praticar diferente.

${ }^{17}$ Como fundamentação da teoria da eticidade pode ser considerado o item da introdução dessa teoria (FdD §§ 142-157). Após a exposição do conceito de eticidade (FdD §§ 142, 143) é apresentado o lado objetivo da eticidade como substância (FdD §§ 142,143) assim como o vir a ser do espírito da substância ética na referência identificadora dos indivíduos com a substância (FdD §§ 146, 147), em uma referência que se expressa no seu modo de ação ética (FdD §§ 148-157).
}

\begin{tabular}{|l|l|l|l|l|}
\hline Qevista 2 ialectus & Ano 2 & n. 3 & Julho-Dezembro 2013 & p. 35-47 \\
\hline
\end{tabular}


ética existindo independentemente dos sujeitos singulares tem que determinar a vontade particular dos sujeitos singulares.

2. Que a ação dos singulares é determinada pelo poder da substância da comunidade ética não significa, para Hegel, que ela está determinada de modo estranho aos indivíduos. Antes pelo contrário, os sujeitos singulares adquirem sua identidade pela relação aos conteúdos dos costumes e das instituições. Eles se identificam de forma emotiva com a substância ética da comunidade. O compromisso para com a comunidade ética não deve ser apenas uma mera proclamação, mas deve ser estabelecido nos costumes diariamente praticados.

3. A autocompreensão ética dos indivíduos é concretamente vivida por todos eles. Ela se manifesta em um modo de ação tornado hábito, e no caráter ético, na virtude e na retidão do preenchimento ético do dever, no qual a boa ação se torna uma certa evidência, isto é, uma prática natural. Apenas na medida em que os indivíduos cumpram os seus deveres éticos independentemente das suas ponderações pessoais e dos interesses particulares, concede-se lhes o direito à sua liberdade subjetiva-moral e o prosseguimento dos seus interesses individuais. ${ }^{18}$

A relação da eticidade e da moralidade em Hegel gostaria de descrever aventando quatro teses:

1. A eticidade e a moralidade se comportam uma a outra como a moral coletivamente praticada e a moralidade individual. Hegel estabelece a prioridade da eticidade frente à moralidade individual. Uma doutrina ética dos deveres é possível para ele apenas no

\footnotetext{
${ }^{18}$ A doutrina dos deveres de Hegel engloba as seguintes espécies principais de deveres:

"I. O homem deve casar-se ( $\$ 160$ anotação); amar o seu cônjuge (§§ 161-162) dentro do matrimônio monogâmico ( $§ 167)$, espiritualizar sua pulsão sexual natural ( $§ 163-166)$, adquirir e bem administrar um patrimônio familiar ( $\S 170-172)$, amar ( $\$ 173)$ e educar suas crianças (§ 174). A criança deve amar os seus pais $(\S 173)$ e lhes obedecer $(\S \S 174-175)$.

II. Como membro da sociedade burguesa ( $\$ 187)$ o indivíduo deve satisfazer suas necessidades e as necessidades de outros pelo trabalho ( $\S 187,196 \mathrm{ss}$.), formar-se $(\S \S 187,197)$ e cumprir os deveres específicos e direitos da sua classe [Stand] ( $\$ 207)$, respeitar os direitos de cada pessoa ( $\S 34-102,134$, 209 ss.), observar as leis ( $\$$ 211ss.), no litígio submeter-se à lei e às regras da administração da justiça ( $\S 219$ ss.), promover o bem-estar universal e o bem-estar de cada indivíduo ( $\S 125,130,134,230$ ss.), colaborar com a educação dos cidadãos (§ 239), aderir a uma corporação e cumprir os deveres lá válidos $(\S \S 250$ ss.).

III. Como cidadão o homem tem que submeter a própria esfera privada (inclusive o direito privado e o bem-estar privado, de si mesmo, de sua família, de sua corporação, de sua classe [Stand] e da sociedade burguesa em geral) ao fim último político ( $\$ \S 268)$ e com a disposição do espírito patriótico de obedecer às leis ( $\$ 268)$. Ele deve participar de modo leal na vida política, tomar a seu cargo e cumprir os deveres do papel político que lhe cabe $(\S \S 237-319,337)$ e, se for necessário, sacrificar-se pelo Estado ( $\S 334$ 328). Aos deveres que o Estado impõe aos seus cidadãos, pertence também o dever de pertencer a uma religião que não contradiga os alicerces do Estado ( $\$ 270$ e anotação); já que o homem sem religião não tem nenhuma consciência dos fundamentos espirituais do Estado; falta-lhe por causa disso, a correta disposição política de espírito" (PEPERZACK, 1997, p. 188s.).
}

\begin{tabular}{|c|c|c|c|c|}
\hline Revista Qialectus & Ano 2 & n. 3 & Julho-Dezembro 2013 & p. $35-47$ \\
\hline
\end{tabular}


terreno da substância ética, porque o princípio da subjetividade moral, com efeito, contém a determinação formal do dever, mas não pode determinar os deveres concretos conteudísticos. Hegel deduz o conteúdo dos deveres do poder da substância ética e das suas exigências. A moral coletivamente praticada da eticidade está ancorada no poder da substância ética. Nela a obrigatoriedade dos deveres éticos têm sua objetividade, enquanto o dever-ser da moral individual permanece como um dever-ser insatisfeito e insatisfazível, sem objetividade.

2. O ponto de vista de Kant do universalismo e da imparcialidade possibilita a intelecção no bem, contudo, ele não pôde conferir a este nenhuma realidade efetiva. Hegel dá ao bem sua efetividade, isso, contudo, em detrimento da sua universalidade e imparcialidade. Ele toma partido manifestamente pela substância ética, à qual ele subordina o indivíduo. Visto que a eticidade apenas é efetiva no Estado, a comunidade ética em Hegel não é universal, mas está restrita aos Estados nacionais particulares respectivos. Os deveres delineados firmemente apenas existem nas comunidades éticas organizadas por Estados nacionais.

3. No âmbito da eticidade, a moralidade está integrada apenas no sentido eticamente não-específico da moralidade: a vontade dos sujeitos singulares deve identificar-se com seus propósitos e suas pretensões. Ela se reduz à identificação subjetiva com as instituições éticas do Estado; isto não representa nenhum aspecto especificamente ético da moralidade. De outra maneira, enquanto direito do sujeito singular que põe ele mesmo a norma e adquire sua orientação da vida a partir da autodeterminação subjetiva, o ponto de vista moral não está integrado. Ele encontra seu papel e sua significação no âmbito da sociedade burguesa.

$\mathrm{Na}$ sociedade burguesa cada um pode conduzir sua vida individual de forma auto-determinada, independente, a partir da sua própria compreensão. Contudo, sob a moral não se compreendem as possibilidades de desdobramento que a sociedade burguesa oferece profissionalmente ao indivíduo. Hegel acentua a possibilidade do engajamento espontâneo altruísta dos indivíduos na sociedade burguesa. Aqui a moralidade tem o significado da disponibilidade subjetiva para o apoio caritativo. Pois a pobreza é um problema que a sociedade burguesa não pode resolver a partir de si mesma. $^{19}$

\footnotetext{
${ }^{19}$ Complementar à entrega dos pobres à moralidade privada (FdD § 207) Hegel propõe como solução do problema da pobreza abandonar a populaça (a plebe) ao seu destino e a remeter à mendicidade pública. Ele defende, portanto, a exclusão político-social da populaça, que mesmo assim está excluída da
} 
4. Hegel se desencontra do terceiro caminho entre a subjetividade moral e a eticidade deparada, no qual os sujeitos singulares chegam racionalmente a acordo sobre sua finalidade conjunta, o bem, na sua socialização ética. A eticidade teria que ser ancorada em uma prática racional da sociedade, em que os indivíduos singulares com seus interesses particulares se mediariam à universalidade.

Esse tal terceiro caminho o jovem Marx perspectivou. De acordo com seu ideal da democracia, numa crítica das relações sociais existentes, a unidade racional dos interesses particulares e universais teria que ser desenvolvida a partir dos sujeitos singulares que trazem ao equilíbrio os seus interesses sociais opostos. ${ }^{20}$

Em relação à questão inicial se deixa dizer resumidamente o seguinte: em Hegel não se encontra nenhum reconhecimento da moral no sentido de que nos âmbitos essenciais da vida os motivos morais dos indivíduos singulares são aceitos, que marcam um limite da competência estatal. Um tal reconhecimento dos motivos morais parece, para ele, uma concessão forte demais do ponto de vista da moral, que põe em perigo a estabilidade do Estado. ${ }^{21}$ Hegel integra a moral na eticidade estatal apenas no sentido eticamente não específico segundo o qual a vontade dos sujeitos singulares deve afirmar interiormente as instituições do Estado. Além disso, ele a entrega ao âmbito da sociedade burguesa, na qual ela empresta serviços úteis de compensação para o Estado, que considera supérflua a assistência político-social dos pobres.

\section{Referências}

ANGEHRN, Emil. Die Ambivalenz der Moderne. Staat und Gesellschaft in Hegels Rechtsphilosophie. In: Hegel-Jahrbuch 1988. H. Kimmerle, W. Lefevre, R. W. Meyer (Orgs.). Bochum: Germinal, 1989

HEGEL, G.W.F. Über die wissenschaftlichen Behandlungsarten des Naturrechts, seine Stelle in der praktischen Philosophie und sein Verhältnis zu den positiven Rechtswissenschaften. In: Werkausgabe in zwanzig Bänden. E. Moldenhauer, K.M. Michel (Orgs.), Vol. 2. Frankfurt am Main: Suhrkamp, 1969.

sociedade burguesa (FdD § 245 anotação). Essa proposta, na verdade, fica em contradição à apresentação da Filosofia do Direito $§ 242$ anotação que seria melhor se os poderes públicos atuassem contra a pobreza do que a caridade privada.

${ }^{20}$ Marx desenvolve o ideal da democracia de uma sociedade política que organiza a si mesma, como consequência da sua crítica à separação do Estado político moderno da sociedade burguesa no seu escrito Kritik des Hegelschen Staatsrechts [A crítica do direito estatal hegeliano] (cf. MARX, 1956, p. 230-234; 316-333). O erro de Hegel consistiria em perceber a oposição do Estado e da sociedade burguesa e, ao mesmo tempo, a negar com sua teoria do Estado como autorrealização da ideia ética.

21 A posição ambígua de Hegel com respeito à publicidade crítica, seu medo das opiniões que desmoralizam o Estado (cf. FdD $\S \S 314-318$ ), parece ser a expressão da sua antipatia frente ao ponto de vista subjetivo-moral. 
Grundlinien der Philosophie des Rechts oder Naturrecht und Staatswissenschaft im Grundrisse. In: Werkausgabe in zwanzig Bänden. E. Moldenhauer, K.M. Michel (Orgs.), Vol. 7. Frankfurt am Main: Suhrkamp, 1969ss.

JERMANN, Christoph. Moralität. In: JERMANN, C. (Org.). Anspruch und Leistung von Hegels Rechtsphilosophie. Stuttgart-Bad Cannstatt: frommann-holzboog 1987, p. $101-144$.

MARX, K. Kritik des Hegelschen Staatsrechts. In: K. Marx \& F. Engels Werke, Bd. 1. Berlin (DDR): Dietz-Verlag, 1956, 203-333.

PEPERZAK, Adriaan Th. Hegels Pflichten - und Tugendlehre. In: HEGEL, G.W.F. Grundlinien der Philosophie des Rechts. Klassiker auslegen. Ludwig Siep (Org.). Berlin: Akademie-Verlag, 1997.

SCHICK, Friederike. Vom Guten, das noch stets das Böse schafft. Hegels Moralitätskritik. In: KOSLOWSKI, P.; LÖW, R.; SCHENK, R. (Orgs). Jahrbuch für Philosophie des Forschungsinstituts für Philosophie Hannover 6. Wien: PassagenVerlag, 1995, p. 47-67. 